\title{
A Supervision Model for Senior Managers of Public State-Owned Enterprises
}

\author{
Yuqiao Li ${ }^{\mathrm{a}}$, Yiwen Yin $^{\mathrm{b},{ }^{*}}$, Yanan Wang ${ }^{\mathrm{c}}$ \\ School of Government Administration, Beijing Normal University, 100875, China \\ a16689379@qq.com, buiryinyiwen@163.com, cbjwya@sina.com
}

Keywords: State-owned enterprises, Principal-agent theory, Supervision and constraint, Multitask model.

\begin{abstract}
Under the modern enterprise system, the owner and the manager of a company are different people, which leads to the problems such as inconsistent goals and asymmetric information between the two, further resulting in principal-agent issues. In state-owned enterprises, in particular, the principal-agent problem is more serious due to the absence of not only their owners but also the monitors. By establishing the principal-agent model, we discuss the supervision and constraint issue of state-owned enterprises in carrying out social tasks. We first set up an optimal supervision model for the principals. Then, we discuss the influence of information symmetry on supervision, propose an incentive-supervision equilibrium model, and substitute incentive with supervision. Finally, in view of the observability of the task, we draw lessons from the incentive-supervision mode on the products and services of non-profit sectors in western countries, and put forward effective suggestions for evaluating and monitoring public SOE.
\end{abstract}

\section{Introduction}

In recent years, while Chinese scholars have advocated the monitoring mode of western countries in China, they have ignored a premise that these foreign companies are private and not state-owned. In China, however, although the reform in modern enterprise system has been carried out following the example of western countries, the supervision and constraint process on managers of state-owned companies has only been improved in form, and the situation has become even more complex in essence.

The supervision of SOE is divided into two parts: internal and external supervision. Internal supervision refers to the supervision conducted by the internal board of directors, the board of supervisors, and the general meeting of shareholders, according to the corporate governance system of modern enterprises. External supervision, on the other hand, means that the companies are supervised by higher authorities, governments, capital markets, and external regulatory bodies. In view of the nature of state-owned enterprises, the responsibilities of supervision and constraint are not restricted by capitalization operation or effective exit mechanism, but by setting up various regulatory bodies.

\section{Theories and Assumptions}

The study of supervision issues and monitor mechanism on senior managers has started very early by many scholars; the proposal of supervision mechanism was even earlier than that of the incentive system. Homeroom (1979) proposed that the principal-agent problem was originated from asymmetric information that was, the agent possessed sufficient information while the principal did not, therefore, "a natural remedy to the problem is to invest resources into monitoring of actions and use this information in the contract”. Maria Maher and Tomas Anderson, et al. (2000) stated that effective monitoring was identical to the effect of incentive. Bedchuk and Fried (2004), Matsumura and Shin (2005), and Jensen and Murphy (2004) all believed that incentive and supervision could be mutually reinforced, that only enhanced supervision could promote the effect of incentive, and that the supervision could substitute agency costs to some extent. Hillock (1997), Benjamin E, et al. (1998), and Martin Lipton (2007) studied the relationship between supervision and agency costs by means of 
modeling and econometric methods, and proved the complementary relationship between the two. John Sessions (2008) showed in his paper that incentive and supervision could substitute each other to some extent, and put forward the supervision function which included the supervision cost, intensity, chance of success, as well as other variables.

Chinese scholars have studied the supervision issues on Chinese state-owned enterprises in accordance with their particularity. Sheila Yang, et al. (2011) stated that the supervision issue was generally discussed in two aspects, internal and external, about how to monitor the managers of SOE by the market, government, law, and their reputations. Feng Kong (2004), taken as an example, has established a supervision function model to analyze the speculation of the agent, as well as a specific function model to analyze the relationship between the optimal supervision scheme and the optimal incentive scheme. Kingie Deng and Jian Hua Li (2006) discussed the principal-agent's check-andbalance mechanism by establishing a supervision cost model, and analyzed the supervision of the board over the managers of state-owned enterprises. Zhizhong Huang (2009) proved that the salary of senior managers was significantly influenced by external supervision. Yankee Li (2011) proved through a venture capital contract model that there existed an optimal allocation of supervision for risk managers, and that the monitoring on risk managers' overconfidence and on their efforts was helpful to motivate them to work harder and reduce the agency costs.

\section{Model Analysis: The Optimal Supervision Model for the Principals}

The way to encourage senior managers to work hard and improve the degree of their effort is not limited in offering the highest salary as incentive to attract them. It also requires supervision to urge them. "Carrot and stick" approach can better improve the degree of effort.

\subsection{Description of the Model}

We assume that the final outputs of an enterprise are influenced by the degree of its supervisor's effort and the uncertainty of the external environment. We write an equation about supervisor's performance asy $=a+\varepsilon$, where $y$ is the outputs or performance of the supervisor, $a$ is the degree of the supervisor's effort, and $\varepsilon$ is the uncertainty of external environment, which is a random variable of normal distribution with a mean value of 0 and a variance of $\sigma^{2} . \varepsilon \sim \mathrm{N}\left(0, \sigma^{2}\right)$. a and $\varepsilon$ determine the observable result of $y(a, \varepsilon)$. We assume that $y$ is the strictly increasing function of $a$, and a concave function, that is, when $\varepsilon$ is given, the outputs or profits increase as the manager pays more efforts. Also, $\mathrm{y}(\mathrm{a})^{\prime}>0$ so that $\mathrm{y}$ is the strictly increasing function of $\varepsilon$, which means $\mathrm{y}$ increases as $\varepsilon$ becomes greater.

We define $c(a)$ as the cost of the supervisor's effort, and $c^{\prime}(a)$ as the marginal cost of the effort. $c^{\prime}(a)$ Is the increasing function ofa, satisfying $c^{\prime}(a)>0, c^{\prime \prime}(a)>0 . c(a)=b a^{2} / 2$, where b is the coefficient of the cost of manager's effort. $b>0$, and the bigger $b$ is, the greater the negative utility or the manager's cost in the same effort is.

The expectation and the variance of the outputs (profits) of the enterprise are

$$
\mathrm{E}(\mathrm{y})=\mathrm{E}(\mathrm{a}+\varepsilon)=\mathrm{a}, \operatorname{Var}(\mathrm{y})=\sigma^{2} \text {. }
$$

The degree of the manager's effort determines the outputs or profits of the enterprise, but has no effect on the variance.

The salary for senior managers is composed of two parts. One is the base pay (fixed), which we define as $\alpha$, and the other is the bonus linked with performance or outputs, which we define as $\beta y$. $y$ Is the outputs (profits) of the enterprise, and $\beta$ is the proportion of the outputs, which also refers to the proportion of risk that the manager should undertake. We assume that shareholders are risk-neutral, and managers are risk averter. The equation of salary contract can be written asw $(y)=\alpha+\beta y$.

We define the probability of the principal discovering that the manager does not reach the target standard ass $\in[0,1]$. It also refers to the supervision ability of the public over the manager. The cost of supervision is $M(s)$, satisfying $\mathrm{M}^{\prime}(\mathrm{s})>0$ and $\mathrm{M}^{\prime \prime}(\mathrm{s})>0$, which means the supervision cost is proportional to the supervision levels, and thus the marginal output rate of the supervision cost is increasing. We further define the supervision cost function as $M(s)=\bar{M} s^{2} / 2$, where $M$ is the coefficient of principal's supervision, and when $s \geq 0$, for a given supervision level, the supervision 
cost is greater as $s$ increases. Whens $=1, M=\bar{M} / 2$, at which point the principal's supervision cost reaches the maximum level. If the manager's performance y does not reach the targetŷ, the manager will be punished by the principal, such as transferred or demoted. If the performance reaches the target, the principal will not implement punishment. We define the punishment value ask $\hat{\mathrm{y}}-\mathrm{y})$, therefore the punishment function for the manager can be written as

$$
\mathrm{k}(\mathrm{y})=\left\{\begin{array}{cc}
\hat{\mathrm{k}}(\hat{\mathrm{y}}-\mathrm{y}) & \mathrm{y}<\hat{\mathrm{y}} \\
0 & \mathrm{y} \geq \hat{\mathrm{y}}
\end{array},\right.
$$

Where $\hat{y}$ is the target which refers to what the principal expect the manager to reach, and $\hat{\mathrm{k}}$ is the punishment coefficient of not reaching the standard. We can calculate the expectation of the manager being punished as follows:

$$
\mathrm{E}[\mathrm{k}(\mathrm{y})]=\mathrm{E}[\mathrm{p} * \hat{\mathrm{k}}(\hat{\mathrm{y}}-\mathrm{y})+(1-\mathrm{p}) * 0]=\mathrm{p} \hat{\mathrm{k}}(\hat{\mathrm{y}}-\mathrm{a}) .
$$

When meeting the conditions of participation constraint, the manager can choose whether to accept the supervision-punishment scheme or not. $\bar{u}$ is the minimum income of the manager, i.e., the lowest acceptable remuneration or the opportunity costs, then only when expect income of accepting the scheme is larger than or equal to the minimum utility $\overline{\mathrm{u}}$, can the conditions of participation constraint be satisfied. Under the assumption that the principal is risk-neutral and the manager is risk-averse, the cost of risk is $\rho \beta^{2} \sigma^{2} / 2$, and the expected utility of the principal and the manager are as follows respectively:

The expected income of the principal,E(u) is

$$
\mathrm{E}[\mathrm{y}-\mathrm{w}(\mathrm{y})+\mathrm{k}(\mathrm{y})]-\mathrm{M}(\mathrm{s})=\mathrm{E}[\mathrm{y}-(\alpha+\beta \mathrm{y})+\mathrm{k}(\mathrm{y})]-\mathrm{M}(\mathrm{s}),
$$

And the expected income of the manager, $\mathrm{E}(\overline{\mathrm{w}})$, is

$$
\mathrm{E}[\mathrm{w}(\mathrm{y})-\mathrm{c}(\mathrm{a})-\mathrm{k}(\mathrm{y})]-\rho \beta^{2} \sigma^{2} / 2=\mathrm{E}[\alpha+\beta \mathrm{y}-\mathrm{c}(\mathrm{a})-\mathrm{k}(\mathrm{y})]-\rho \beta^{2} \sigma^{2} / 2,
$$

And the relationship between the principal and the manager is

\subsection{Supervision with Symmetric Information}

$$
\left\{\begin{array}{c}
\max _{\beta, \alpha, s}(u) \\
\text { s.t. }(I R) E(\bar{w}) \geq \mu^{0} \\
\text { (IC) } a^{*} \in \operatorname{argMaxE}(\bar{w})
\end{array} .\right.
$$

Under the condition of symmetric information, the degree of the manager's effort is observable, the target of the state-owned enterprise is clarified, and the performance is measurable. We can use economic indicators or social satisfaction as observable indicators, so that the unobservable effort can be converted as observable. Under the optimal salary incentive, the principal should choose $(\alpha, \beta)$ and a to solve the following optimal problem. When the information is symmetric, it is not necessary to consider the incentive compatibility constraint to solve the dynamic game. When only considering the participation constraint, we can find

$$
\left\{\begin{array}{c}
\max _{\beta, \alpha, \mathrm{a}}=(1-\beta) a-\alpha \\
\text { s.t. (IR) } \alpha+\beta a-\mathrm{ba}^{2} / 2-\rho \beta^{2} \sigma^{2} / 2 \geq \mu^{0}
\end{array}\right.
$$

Under the optimal condition, the equation of participation constraint is established. We substitute the fixed salary $\alpha$ into the target function, then the optimal problem can be expressed as:

$$
\max _{\beta, \alpha, \mathrm{a}}\left(\alpha-\mathrm{ba}^{2} / 2-\rho \beta^{2} \sigma^{2} / 2-\mu^{0}\right) \text {. }
$$

The principal subtracts the cost of effort by maximizing deterministic equivalent income, and with givenū, the optimal first order condition is

$$
\mathrm{a}^{*}=1 / b ; \beta^{*}=0 .
$$

We substitute the result into the participation constraint equation:

$$
\alpha^{*}=\mu^{0}+b\left(a^{*}\right)^{2} / 2=\mu^{0}+1 / 2 b .
$$

Here we get the Pareto optimal contract. Since the principal is risk-neutral and the agent is riskaverse, under the optimal contrast, the agent should not bear any risk. Therefore, $\beta^{*}=0$ the total remuneration received by the agent is equal to the sum of the minimum income and the cost of effort, i.e., $a b=1$ and we find thata* $=1 / b$. 


\subsection{Supervision with Asymmetric Information.}

When the degree of the manager's effort is unobservable, the supervision and punishment model changes. If the target of the state-owned enterprises is not clear and the performance is not measurable, the manager's effort becomes hidden information which cannot be observed by the principal. The principal has to take incentive and constraint measures in order that the manager can make different choices. Under this circumstance, the importance of incentive becomes obvious, or say, only when the manager's effort is unobservable, the incentive can be meaningful. We can find the optimal solution and the optimal effort level:

$$
\left\{\begin{array}{c}
\max _{\beta, \alpha}(1-\beta) a-\alpha \\
\text { s.t. (IR) } \alpha+\beta a-\mathrm{ba}^{2} / 2-\rho \beta^{2} \sigma^{2} / 2 \geq \mu^{0} \\
\text { (IC) } \mathrm{a}=\beta / b
\end{array}\right.
$$

Then we substitute the manager's participation constraint and the incentive compatibility constraint into the target function:

$$
\left\{\begin{array}{c}
\max _{\beta}\left(\beta / b-b / 2(\beta / b)^{2}-\rho \beta^{2} \sigma^{2} / 2-\mu^{0}\right) \\
\beta^{*}=1 /\left(1+b \rho \sigma^{2}\right)
\end{array}\right.
$$

$\beta$ Is the decreasing function of $b, \rho$, and $\sigma^{2} . \beta$ And $b$, the coefficient of the cost of effort, are the main factors that influence the degree of manager's effort. If $\beta$ is high while $b$ is low, the manager will probably choose to work hard, then the risk to undertake will be low.

When the manager's effort is unobservable, the shareholders should offer incentive performance pay to the manager so that the manager can participate in the allocation of the surplus, and further, the manger will pay more effort. So we get the optimal effort under the unobservable condition:

$$
\mathrm{a}^{*}=\beta / b=1 / b\left(b \rho \sigma^{2}+1\right)
$$

We learn from this equation that when the information is asymmetric and when the manager's effort is unobservable, the manager chooses less effort. Also, both the base pay and the performance pay are effected by risk type $(\rho)$, the risk of external market $\left(\sigma^{2}\right)$, and the coefficient of the cost of effort $(b)$.

By comparative statics analysis, we find that

$$
\frac{\partial \alpha^{*}}{\partial \delta^{2}}<0, \frac{\partial \beta^{*}}{\partial \mathrm{b}}<0, \frac{\partial \beta^{*}}{\partial \rho}<0
$$

The above formulae show that when the cost of effort for the manager of SOE is high, the risk is low, and for the manager who is the risk averter, the risk to undertake is low. When the risk of the enterprise becomes higher, the risk for the agent will be lower. So the efficient incentive policy for the principal of the state-owned enterprises is based on the observable effort, whereas the discussion above is under the circumstance that the observation is cost-free. In fact, the cost occurs in observing the manager of the SOE, and it may affect the principal's choice.

\subsection{Solution to the Incentive-Supervision Model and the Equilibrium.}

The cost of observing the manager of SOE is the supervision cost. The manager is observed through the outputs of the company, how the target is realized, the comments of third parties, public's satisfaction, etc. If the target is not accomplished, or the moral hazard is noticed through supervision, the higher authorities can punish the manager.

The supervision cost $\mathrm{M}(\mathrm{s})$ increases as the supervision level s rises, and $\mathrm{s} \neq 0$. The optimal strategy for the manager is

And the maximum equation is

$$
\mathrm{E}[k(\mathrm{y})]=\mathrm{E}[(1-\mathrm{s}) * 0+s(\hat{\mathrm{y}}-\mathrm{y}) \hat{\mathrm{k}}]=s(\hat{\mathrm{y}}-a) \hat{\mathrm{k}}
$$

$$
\max _{\mathrm{a}}(\overline{\mathrm{w}})=\alpha+\beta a-\mathrm{ba}^{2} / 2-\hat{\mathrm{k}}(\hat{\mathrm{y}}-a) s-\rho \beta^{2} \sigma^{2} / 2
$$

We take the derivative with respect to equation (9), and with $\partial \mathrm{E}(\overline{\mathrm{w}}) / \partial \mathrm{a}=0$, we find

$$
\mathrm{a}=\beta+s \hat{\mathrm{k}} / b>\beta / b \text {. }
$$

Therefore, after the supervision over the manager, the degree of manager's effort is higher than that under the incentive contracts. Moreover, if only the incentive is considered and the constraint is ignored, the manager's effort $a=\beta / b<1 / \mathrm{b}$, thus the Pareto optimal not realized. But if the 
supervision exists, the constraint to the manager will be enhanced, and the manager's effort will be closer to the Pareto optimal. So when considering the optimize contract under supervision:

$$
\left\{\begin{array}{c}
\operatorname{maxE}_{\beta, \alpha, \mathrm{s}}(\mathrm{u})=a-\alpha-\beta a-\bar{M} \mathrm{~s}^{2} / 2+s(\hat{\mathrm{y}}-a) \hat{\mathrm{k}} \\
\text { s.t. (IR) } \alpha+\beta a-\mathrm{ba}^{2} / 2-\mathrm{s}(\hat{\mathrm{y}}-a) \hat{\mathrm{k}}-\rho \beta^{2} \sigma^{2} / 2 \geq u^{0 .} \\
\text { (IC) } \mathrm{a}=\beta+s \hat{\mathrm{k}} / b
\end{array}\right.
$$

We substitute a and $\alpha$ in (10) into the target function and find that the optimal solution of $\beta$ and $s$ under the first order derivative:

$$
\begin{aligned}
& \partial \mathrm{E}(\mathrm{u}) / \partial \beta=0, \beta=(1-\mathrm{s} \hat{\mathrm{k}}) /\left(\mathrm{b} \rho \delta^{2}+1\right), \\
& \partial \mathrm{E}(\mathrm{u}) / \partial \mathrm{s}=0, \quad \mathrm{~s}=\hat{\mathrm{k}}(1-\beta) /\left(\widehat{\mathrm{k}}^{2}+\overline{\mathrm{M}} \mathrm{b}\right) .
\end{aligned}
$$

In equation (11), $\beta=(1-\mathrm{sk}) /\left(b \rho \delta^{2}+1\right)<1 /\left(b \rho \delta^{2}+1\right)$, the latter is the value of $\beta^{*}$ (when supervision is not considered). It is because the value of the numerate in $\beta$ is smaller. When supervision becomes strict, the value of s gets bigger, and the punishment coefficient $\hat{\mathrm{k}}$ gets higher, which indicates that the effect of supervision to incentive is smaller, the manager get less bonus, and are willing to undertake less risk. The manager of SOE tends to choose fixed pay.

Equation (12) is a supplement to (11), which indicates that incentive and supervision are complementary. If the incentive coefficient (risk coefficient) $\beta$ rises, the supervision level s will decrease, and if the supervision level $s$ is increased, the incentive coefficient (risk coefficient) $\beta$ will decrease. So the principal should find the balance between incentive and supervision to make the optimal choice for the incentive-supervision strategy.

\subsection{Analysis of the Result}

From the supervision-punishment design for the managers of SOE, we find that when $\beta=0,1-$ $s \hat{\mathrm{k}} \neq 0$ will not happen, so the denominatorb $\rho \delta^{2} \rightarrow \infty$, and the absolute risk coefficient $\rho \rightarrow \infty$. Given that the managers are risk averter when $\rho>0$, so under this condition, the managers are absolute risk averters who are unwilling to take any risk. Then, only the fixed pay is needed for the managers, and the supervision level $s=\hat{\mathrm{k}} /\left(\hat{\mathrm{k}}^{2}+\overline{\mathrm{M}} \mathrm{b}\right)>\hat{\mathrm{k}}(1-\beta) /\left(\hat{\mathrm{k}}^{2}+\overline{\mathrm{M}} \mathrm{b}\right)$, is the highest. When $\beta=1, s=0$ and $\rho=0$, the principals are risk-neutral, and the managers will undertake all risk and get all revenue. Also under this condition, the targets of the principals and the agents completely match, so supervision on managers is not required, the probability of which is very small. When $0<\beta<1$, we find that $\mathrm{s}^{*}=\hat{\mathrm{k}} /\left(\hat{\mathrm{k}}^{2}+\overline{\mathrm{M}} \mathrm{b}+\overline{\mathrm{M}} / \rho \delta^{2}\right)$, and substituting the optimal supervision level into (11), we find that $\beta^{*}=1 /\left(1+\rho \delta^{2} \widehat{\mathrm{k}}^{2} / \overline{\mathrm{M}}+\mathrm{b} \rho \delta^{2}\right)$, which is the optimal strategy for the principals. Therefore, if the principals and the managers undertake the target risk together, the principals will choose to monitor the managers, and the supervision level can be lower than the level with no incentive. It indicates that incentive and supervision are complementary as well. By comparative statics analysis of $(\rho),\left(\delta^{2}\right),(b),(\overline{\mathrm{M}})$, and $\mathrm{s}^{*}$, we find that

$$
\frac{\partial \mathrm{s}}{\partial \rho}>0, \frac{\partial \mathrm{s}}{\partial \delta^{2}}>0, \frac{\partial \mathrm{s}}{\partial \overline{\mathrm{M}}}<0 .
$$

The supervision level of the principals is proportionate to the risk appetite of the managers. If the managers are risk-biased, the principals should increase the supervision level to prevent the possible errors or deviations from the managers. If the managers are risk-neutral or risk-averse, then the principals should reduce the supervision cost and increase the incentive cost, so that the managers will pay more effort. $\partial s / \partial \overline{\mathrm{M}}<0$, as the supervision cost increases, the marginal supervision level is diminishing. Therefore, it is not that everything will increase with higher supervision cost.

\section{Enlightenment and Suggestions}

\subsection{Simplifying the Principals' Supervision Structure.}

According to the theory of transaction cost, if the structure inside the companies is complex, the transaction cost will be high. If the structure is simplified, the lag of determination and action will be short, so that the managers can solve problems efficiently. Therefore, simplify the structure is an effective way to reduce the transaction cost. In state-owned enterprises, the principal-agent relationship is two-way and multi-leveled, from the initial owners to the ultimate performance, so is 
the supervision process. The difficulty of revealing information, derived from information asymmetry, becomes greater as the supervision complicity increases.

With the improvement in economic globalization and democratization, people are paying more attention to the issue of government corruption, thus the requirement to the government is higher. Cutting the levels and simplifying the structure of the government can not only expose the information more efficiently and reduce the level of information asymmetry, thereby reducing corruption, but also can improve the effect and reduce the cost of tackling corruption. It will also be helpful to build a service-oriented, honest, and responsible government.

\subsection{Encouraging Wide Public Supervision.}

The public should be widely involved in observing and monitoring the behavior of state-owned enterprises in order to ensure the implementation of the regulations. Laws and contracts can be sued to restrict and manage the discretion, and the public can be attracted to supervise to ensure the symmetric information between the regulatory bodies and the manager. Symmetric information includes the information that is approachable to the public and the managers' targets. It will help state-owned enterprises effectively offer services to social development.

Under the framework of utility regulation, incentive rate is very common in the utility sectors. Incentive rate is a tool to encourage large business or industrial clients to serve in utilities or maintain public facilities. It is a kind of discount based on the utility companies' standard rates, terms or conditions.

\subsection{Establishing Third-Party Supervision Agencies.}

In order to make sure that the independent third-party agencies, under the protection of the law, serves those who represent the common interests of most people rather than the interests of a few related parties (such as the higher authorities), these independent agencies should keep up long-term relationships with the supervised state-owned enterprises, consumers, other stakeholders, and the governments.

There are supervisory bodies or advisory institutions provided by the governments, but we should be aware that these institutions may become the tools for politicians or special interest groups. The supervision procedure has two steps, first the public providing information to the agencies, and second, the appealing solved by a middle-level management institution. All stakeholders are allowed to express their opinions through methods such as public hearing.

\subsection{Enhancing the Transparency of Supervision.}

Among different types of state-owned enterprises, public SOE should be the main object of enhancing the transparency of administrative supervision. It is determined by the business nature. The supervision with public participation is the most important method to monitor the public state-owned enterprises, the governments, and the regulatory bodies, the premise of which is how transparency the information is disclosed. The problem of asymmetric information between the public, public enterprises, and the governments can be better solved if the transparency is enhanced, and further, the developing efficiency of public state-owned enterprises will be improved. We can improve the technique of supervision through internal training and other technologies provided by global management committees, as well as other resources such as regional supervision associations and universities.

\section{References}

[1] Holmstrom B, Milgram P. Aggregation and Linearity in the Provision of Intertemporal Incentive [J]. Cowles Foundation Discussion Papers, 1985, 55 (2): 303-328.

[2] Holmstrom B, Milgram P. Multitask Principal-Agent Analyses: Incentive Contracts, Asset Ownership, and Job Design [J]. Journal of Law Economics \& Organization, 1991, 7 (Special Issue, 24-52.

[3] Dassel A, Mukherjee B, and Sheffield R, et al. Corporate Governance: Effects on Firm Performance and Economic Growth [J]. Scorn Electronic Journal, 2000, 3 (2): 69-77.

[4] Bebchuk L A, Fried J M. Pay without Performance [J]. Business Ethics Quarterly, 2004, 20 (3): 5-24. 
[5] Matsumura E M, Shin J Y. Corporate Governance Reform and CEO Compensation: Intended and Unintended Consequences [J]. Journal of Business Ethics, 2005, 62 (2): 101-113.

[6] Jensen M C, Murphy K J, Wrack E G. Remuneration: Where We've Been, How We Got to Here, What are the Problems, and How to Fix Them [J]. Social Science Electronic Publishing, 2004, 2 (5459): 122.

[7] Hillock K F. Reciprocally Interlocking Boards of Directors and Executive Compensation [J]. Journal of Financial \& Quantitative Analysis, 1997, 32 (3): 331-344.

[8] Benjamin E. Herman. Toward an economic theory of leadership: Leading by example [J]. Working Papers, 2001, 88 (5): 1188-1206.

[9] Lipton M, Rowe P K. The Inconvenient Truth about Corporate Governance: Some Thoughts on Vice-Chancellor Shrine’s Essay [J]. Journal of Corporation Law, 2007, 33 (1): 63-71.

[10] Michael g W, Aaron E, John S, et al. Horizontal Measurement Performance of Five MappingGrade Global Positioning System Receiver Configurations in Several Forested Settings [J]. 2008, 23 (3) (3): 83-88.

[11]YANG Sheila. The Incentive and Supervision Mechanism for State-owned Enterprises [M]. Science Press, 2011.

[12]KONG Feng, LIU Hengyang, QI Jinxing. Game Analysis of Project Managers' IncentiveCompensation Mechanism and Enterprise Supervision [J]. Chinese Journal of Management and Science, 2004, 12 (5): 120-123.

[13]DENG Kingie, LI Jian Hua. Research on the Supervision Mechanism for Managers' Behavior of State-owned Enterprises [J]. System Engineering, 2006, 24 (9): 58-60.

[14]HUANG Zhizhong, XI Qu. Does the Compensation System Consider External Supervision? Evidence from Chinese Listed Companies [J]. Nunki Business Review, 2009, 12 (1): 49-56.

[15]LI Yankee, ZHOU Fang. An Incentive Contract Model for Venture Capitalist Based on the Principal-agent Relationship [J]. Chinese Journal of Management, 2011, 8 (6): 872. 